\title{
PERINATAL LESSONS FROM THE PAST
}

\section{Sir Robert Hutchison (1871-1960) of London and the causes and treatment of rickets}

\section{P M Dunn}

Arch Dis Child Fetal Neonatal Ed 2005;90:F537-F539. doi: 10.1136/adc.2004.065458

A general physician with a special interest in nutrition and in children, Sir Robert Hutchison became a leader in medicine and paediatrics in the United Kingdom during the early decades of the 20th century. His wisdom and wit educated and amused successive generations of students and doctors.

Correspondence to:

Professor Dunn,

Department of Child

Health, University of

Bristol, Southmead

Hospital, Southmead

Bristol BS10 5BN, UK:

P.M.Dunn@bristol.ac.uk

Accepted 6 April 2005
$\mathrm{R}$ obert Hutchison was born on 28 October 28 1871 at Kirkliston, West Lothian, a few miles from Edinburgh. He was the youngest of seven children of Robert Hutchison, a wine Collegiate School, Edinburgh, he entered the University Medical School at the age of 17. A brilliant student, he graduated with first class honours in 1893 at the age of 21, gaining the Ettles Scholarship and medals in every subject except physics. As a pupil of John Thomson he had become interested in children's diseases. After house jobs in obstetrics, medicine, and paediatrics in Edinburgh, he visited Strasbourg and Paris before returning to Edinburgh to work in the physiology department of the university. In 1896 he proceeded to MD and MRCP (Ed) and in 1897, after gaining the $\operatorname{MRCP}(\mathrm{L})$, moved to London, where, on the recommendation of Thomson, he was appointed house physician to Thomas Barlow at Great Ormond Street Hospital (GOS). ${ }^{1}$ That year he wrote with $\mathrm{H}$ Rainy his famous text Clinical methods, ${ }^{2}$ the invaluable handbook for many succeeding generations of young doctors. Between 1897 and 1900, Hutchison worked in the physiology department of the London Hospital Medical College, teaching and undertaking research under the direction of Dr Leonard Hill. His second book Food and dietetics was published in 1900, and the same year he was appointed assistant physician to both The London Hospital and to GOS. He also set up in private practice as a general physician with special interests in digestive disorders and the diseases of children. He was $29 .{ }^{1}$

In 1903 Hutchison received the $\operatorname{FRCP}(\mathrm{L})$ and in 1904 published yet another book which again passed through many editions. Based on his teaching at the London Hospital, it had the title Lectures on the diseases of childhood. ${ }^{3}$ It is from the first edition that the following excerpts on rickets are taken.

\section{On the prevalence of rickets ${ }^{3}$}

"Gentlemen, I shall ask you today to study with me a nutritional disorder, which has the merchant, and Mary Tait. Educated at the peculiarity that it is found in children only-I mean rickets ... I think one can be pretty sure that (the incidence) has increased, because all those factors which tend to predispose to rickets are such as are daily becoming more pronounced. One of those factors is that inability on the part of women to nurse their own children ... another is the increase in women's work ... in many of the large industrial towns rickets is extremely prevalent, for the reason that women to go work in the factories, and their children are left at home badly looked after and improperly fed. A third factor in the production of rickets is found in the tendency for the population to be crowded together in large cities... Now so potent are these factors ... that in many towns more than half of the children seen in the outpatient room exhibit the disease in a more or less marked degree. So the dictum ... still holds good that 'rickets is the most common, and, in its indirect results, the most fatal of all the diseases which peculiarly affect children'."

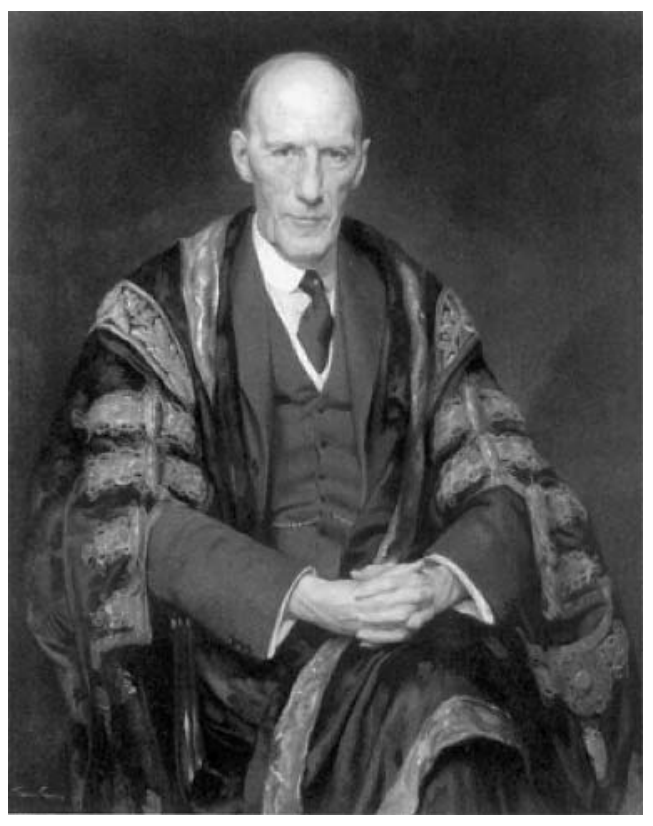

Figure 1 Sir Robert Hutchison, Bt (1871-1960). Painted by James Gunn in 1939. 


\section{On the causes and treatment of rickets ${ }^{3}$}

"... rickets is due to a deficiency of the diet of fat and proteids ... it is probably, in most cases, the deficiency of both of these which has produced the disease. But why it is that rickets should result from such a deficiency no one has yet explained ... This brings us to the consideration of what the treatment of rickets should be ... your first care should be to alter the child's food ... in many cases your first task must be to correct any digestive disturbance which exists. You may have to treat diarrhoea, or gastric catarrh, or want of appetite; and having done that you change the diet ... diminish the amount of starchy things, and increase the amount of proteids and fat. Practically that resolves itself into increasing the proportion of cow's milk and administering cod-liver oil. Of course, if the child can get plenty of cream you can dispense with the codliver oil. But always increase the amount of milk ... The yolk of egg is also very useful in these cases ... (and) many ... also do well with the addition of raw meat juice to their food ... About lime salts you need not trouble; there is no occasion to administer them artificially, for milk contains them in abundance. Nor will drugs help you much, unless you call cod-liver oil a drug. If the child is anaemic, give iron in addition. Many people give phosphorus, but I am not convinced that it makes much difference. Attention to the diet and improving the child's hygienic surroundings must be your chief lines of attack, because although it is true that bad diet is the main cause, yet there are other cooperating factors. Want of sunlight is considered to be one of these. The child should have the benefit of the sun if there is any, and attention should be paid to ventilation, bathing, and clothing."

To place Hutchison's views in the context of the times, it should be recollected that it was only in 1883 that Thomas Barlow had shown that infantile scurvy and rickets were two separate diseases. In 1884 Kassowitz noted a seasonal variation in the incidence of rickets, with a rise during the winter months. After this, Palm (1890) suggested the curative value of sunlight. Although there were many theories as to causation, the general view was that rickets was an essentially dietetic and hygienic condition. Some doctors recommended cod liver oil, after its earlier use by Trousseau in the mid-nineteenth century. However, in 1912, Hutchison's colleague G F Still wrote: "there seems to be no specific virtue in cod-liver oil". ${ }^{4}$

In 1906 Frederick Gowland Hopkins (1851-1947) had proposed the concept of essential accessory food factors, later known as vitamins, and in 1919 Edward Mellanby, experimenting with puppies, showed that it was possible to induce rickets by keeping them on a diet lacking a vitamin that could be shown to be present in cod-liver oil. ${ }^{5}$ It is of interest that, when Mellanby presented his findings to the Royal Society of Medicine in 1920, his work was severely criticised. One commentator deplored "the present craze for vitamins", and Robert Hutchison himself agreed that they were merely "the latest dietetic stunt". ${ }^{6}$ However, the following year McCollum and his colleagues in Baltimore obtained proof of both the existence and curative value of what they named Vitamin D. Meanwhile, the value of sunlight was confirmed by Hulchschinsky (1919), and in 1924 Hess demonstrated that it was possible with ultraviolet light to induce anti-rachitic activity in linseed oil. Three years later Windaus showed that this anti-rachitic substance was ergosterol. In 1928 Parsons $^{7}$ summed up: "The modern view is that the disease is a general nutritional or metabolic disorder which affects every system of the body, the early symptoms bearing no direct reference to the skeleton. Thus rickets may show itself as a respiratory disorder in recurring attacks of bronchitis; as a gastro-intestinal affection in recurring diarrhoea; as a nervous disorder in tetany, convulsions, etc; as in a muscular disease in severe hypotonia; but eventually characteristic bone changes always occur."

Returning to 1904, Hutchison's meteoric career continued. In that year he was invited to give the Goulstonian lectures on the anaemia of infancy. In 1907 he became a founding editor of the Quarterly Journal of Medicine. During the Great War he was medical advisor to the Ministry of Food and in 1917-18 was appointed full physician to both The London Hospital and GOS. In 1931 he was invited to give the Harveian Oration. $^{8}$ The same year he was made Hon FRCP(Ed), and in 1934 he became president of the Royal Society of Medicine. That year he resigned from the staff of The London Hospital and GOS and was instead appointed consulting physician to both. In 1938 he succeeded Lord Dawson of Penn as president of the Royal College of Physicians, and in 1939 was created a baronet in the Birthday Honours. In addition, he received the LLD of Edinburgh and Birmingham, the Hon DSc of Oxford and the Hon MD of Melbourne. He contributed to many national and medical committees and was an active member of the BMA for 65 years. In 1951 the Archives of Disease in Childhood published an issue in his honour. It included a list of his 14 books and 260 other writings. ${ }^{1}$

In 1905 Robert Hutchison had married Laetitia Moore-Ede, a newly qualified doctor at The London Hospital, and they had two sons and a daughter. In 1940 when their home in London was bombed they moved to Streatley in Berkshire. There they celebrated their golden wedding in 1955. Hutchison's health had never been very good. For 20 years he suffered from a duodenal ulcer until having a gastrojejunostomy at the age of 48. Four years later he developed progressive muscular atrophy. However, in spite of these problems he lived to the age of 88, dying in 1960 . His passing was deeply mourned. Dr Donald Hunter, ${ }^{1}$ who had helped to found the British Paediatric Association in 1928, wrote: "In Robert Hutchison Scotland presented to England a young man who was destined to become a superb physician, an eminent scholar, a great writer, a most inspiring teacher, a shrewd and gifted clinician, and above all a most kindly gentleman. Although his career was so outstanding and successful he remained always modest and unassuming. He inspired real affection in those with whom he worked. His shafts of wit sent home his teaching points and his powers of instruction inspired a large number of physicians and paediatricians ... in order to think of him at work one has to conjure up a tall, slightly stooping, rather gaunt figure, dignified and somewhat austere, but a little sorrowful. His features were aquiline, but he had great liveliness of facial expression. His attitude was striking and dignified ... His mode of thought was strikingly accurate and judicial, and often his choice of words was most fastidious". Bernard Schlesinger ${ }^{1}$ added: "Walking round the old Alexandra Ward at Great Ormond Street, I can imagine still a tall gaunt figure, dressed in a grey frock-coat, taking a sniff at some fragrant flower before putting it in his buttonhole and saying 'Thank you, my dear' to the little girl who by custom presented it to him every Monday morning when he entered his ward."

Hutchison's many sayings were treasured. ${ }^{9}$ One anecdote by Hugh Cameron ${ }^{10}$ must suffice: "On listening to a speaker who in his scientific communication reached a remarkable conclusion on evidence clearly insufficient and manifestly false, Robert Hutchison elongated himself to his full height and said: "I observe that the speaker has entitled his remarks 'a preliminary communication'. I think that he would be 
well-advised to make it also a final communication." In 1953 Hutchison had written, and it may serve as his epitaph: "I think there should be a new petition in the litany to be read in hospital chapels or wherever doctors and nurses do, or ought to, congregate. It might be as follows:

"From inability to let well alone; from too much zeal for the new and contempt for what is old; from putting knowledge before wisdom, science before art, and cleverness before common sense; from treating patients as cases, and from making the cure of the disease more grievous than the endurance of the same, Good Lord, deliver us."'"

\section{REFERENCES}

1 Obituary. Sir Robert Hutchison, Bt, MD, LLD, DSc, FRCP, Hon FRCP (Ed). BMJ 1960;i:571-3.

2 Hutchison R, Rainy H. Clinical methods. London: Cassell and Co, 1897.

3 Hutchison R. Rickets. In: Lectures on diseases in children. London: Edward Arnold, 1904:107-21.

4 Guy RA. The history of cod-liver oil as a remedy. Am J Dis Child 1923;26:112-16.

5 Mellanby E. An experimental investigation on rickets. Lancet 1919;i:407-12.

6 Hunting P. The history of the Royal Society of Medicine. London: RSM Press, 2002:311.

7 Parsons LG. Some recent advances in our knowledge of rickets and allied diseases. Lancet 1928;ii:433-8.

8 Hutchison R. Harvey: the man, his method and his message for us today. Oxford: Clarendon Press, 1931.

9 Hunter D. The sayings of Robert Hutchison. Arch Dis Child 1951;20:467-8.

10 Cameron HC. The British Paediatric Association, 1928-1952. London: The British Paediatric Association, 1955:19. 